ORIGINAL ARTICLE

\title{
Organisational and occupational risk factors associated with work related injuries among public hospital employees in Costa Rica
}

\author{
D Gimeno, S Felknor, K D Burau, G L Delclos
}

Occup Environ Med 2005;62:337-343. doi: 10.1136/oem.2004.014936

See end of article for authors' affiliations

Correspondence to:

Dr S A Felknor, Southwest Center for Occupational and Environmental Health, The University of Texas School of Public Health, PO Box 20186, Houston, Texas 77225-0186, USA; Sarah.A.Felknor@.uth.tmc. edu

Accepted 1 December 2004

\begin{abstract}
Aims: To explore the relation between occupational and organisational factors and work related injuries (WRI) among public hospital employees in Costa Rica.

Methods: A cross-sectional survey was conducted among a stratified random sample of 1000 employees from 10 of the 29 public hospitals in Costa Rica. A previously validated, self-administered questionnaire which included occupational and organisational factors and sociodemographic variables was used. From the final eligible sample $(n=859$ ), a total of 842 (response rate 98\%) questionnaires were returned; 475 workers were analysed after excluding not-at-risk workers and incomplete questionnaires. WRI were computed for the past six months.

Results: Workers exposed to chemicals $(R R=1.36)$ and physical hazards ( $R R=1.26)$ had higher WRI rate ratios than non-exposed workers. Employees reporting job tasks that interfered with safety practices $(R R=1.46)$, and a lack of safety training $(R R=1.41)$ had higher WRI rate ratios than their counterparts. Low levels of safety climate $(R R=1.51)$ and safety practices $(R R=1.27)$ were individually associated with an increased risk of WRI. Also, when evaluated jointly, low levels of both safety climate and safety practices showed the highest association with WRI (RR = 1.92).

Conclusions: When evaluated independently, most of the occupational exposures and organisational factors investigated were significantly correlated with an increased injury risk. As expected, some of these associations disappeared when evaluated jointly. Exposure to chemical and physical hazards, lack of safety training, and low levels of safety climate and safety practices remained significant risk factors for WRI. These results will be important to consider in developing future prevention interventions in this setting.
\end{abstract}

S afety climate has been described as the shared assessments of safety policies, procedures, and practices in work organisations ${ }^{12}$ and the perceptions and expectations employees have of safety in their workplace. ${ }^{3}$ These can be viewed as the environment that drives worker behaviour with respect to safety practices. ${ }^{5}$ Consequently, in the past years several studies have been conducted to investigate the hypothesis that improved safety climate should increase compliance with safety practices and decrease work related injuries. In these studies, safety climate has been consistently shown to be a significant predictor of safety practices and workplace injuries. ${ }^{6-8}$

The application of safety climate and safety practices to the healthcare setting and hospital based healthcare workers is evident. Research among healthcare workers in the United States $^{6-13}$ has identified safety climate as one of the most consistently significant predictors of compliance with safety practices, and improved compliance has been documented to result in a decrease in occupational injury.$^{14-17}$ Certain factors, including management commitment to safety and adequacy of resources, are more prevalent in low injury rate companies than high injury rate companies. ${ }^{3}$ However, these factors are unlikely to be present at a desirable level in developing countries, and little is known about whether those previous findings can be extrapolated to other countries, particularly to developing countries. There has been only one previous study of the Costa Rican public hospital system, which showed a very poor safety climate level. In that study, safety climate was found to be a significant predictor of workplace injuries and safety practices. ${ }^{17}$

Safety climate is an organisational level construct that has been evaluated independently in terms of its ability to predict workplace injuries. ${ }^{15-17}$ Safety practices can be considered primarily an individual level variable that is motivated and influenced by larger organisational level constructs (that is, workplace safety policies, supervisor and co-worker influence, and organisational rewards). ${ }^{15}{ }^{18}$ Both safety climate and safety practices have been shown to significantly predict workplace injury. However, these associations have been evaluated independently. To better characterise the interaction of key variables and to guide injury risk prevention efforts, we examined the relation between occupational and organisational risk factors with work related injuries among public hospital workers in Costa Rica. A better understanding of these relations has potential implications for the design of interventions aimed at reducing workplace injuries. The aim of this study was to assess the relation of occupational and organisational risk factors with work related injuries among public hospital based employees in Costa Rica.

\section{METHODS}

Study design and sample selection

In 1997, a cross-sectional survey was conducted among public hospital employees in Costa Rica to collect baseline data for the development of a safety training programme to improve safety practices and to better characterise work related injuries. The survey was repeated in 2000 among the current employees of the same 10 hospitals surveyed in 1997. There were 29 hospitals in Costa Rica at the time of the 1997 and 2000 surveys which were administered by the Caja Costarricense de Seguro Social (Costa Rican Social Security System, CCSS). The CCSS is the largest employer in Costa Rica, and at that time approximately 19000 employees 
Main messages

- Organisational factors had a higher impact on work related injuries among healthcare workers than occupational risk factors.

- The interaction of low levels of both safety climate and safety practices showed the highest association with work related injuries.

- High levels of either safety climate or safety practices showed protective effects on injury risk.

- To confirm these results further prospective multilevel research is needed.

worked in public hospitals. Data for the present study were drawn from the survey conducted in 2000.

In the CCSS system, hospitals are categorised by size, complexity, and type. National hospitals are generally the largest and most specialised, employing $50 \%$ of all public hospital based workers. Regional hospitals are mid-sized and provide basic care plus some specialties, and employ $30 \%$ of all hospital employees. Peripheral hospitals are the smallest, providing only basic medical and surgical services with $20 \%$ of all employees. To obtain a representative sample, 10 hospitals (more than 33\% of all CCSS hospitals) were selected from a stratified sample of all types of hospitals in proportion to the number of employees in each stratum. Five hospitals $(50 \%)$ were drawn from among the national hospitals, three $(30 \%)$ from the regional hospitals, and two $(20 \%)$ from the peripheral hospitals.

As in the 1997 study, payroll lists were provided by the CCSS Human Resources Department, and a simple random sample of 100 employees was selected from each of the 10 study hospitals, providing an initial sample of 1000 employees to be surveyed..$^{17}$ The study protocol was approved by The University of Texas-Houston Health Science Center Committee for the Protection of Human Subjects.

A self-administered questionnaire based on well validated scales, and previously adapted to Costa Rican Spanish language was used. ${ }^{6}{ }^{17}$ The questionnaire was designed based on previous surveys used in hospital settings to assess safety climate and factors associated with employee safety practices. The initial questionnaire was designed to describe the factors associated with compliance with universal precautions among hospital based healthcare workers, ${ }^{6}$ and was conducted in the United States at three regional hospitals in Baltimore, Houston, and Minneapolis. The key construct of safety climate and its relation to individual and organisational factors was originally developed at this time and the item scales associated with these variables have undergone validity testing and factor analysis. ${ }^{6}{ }^{19}$ Content validity was established through previous literature review.

The questionnaire was translated from the original English into Spanish by a native Spanish speaking healthcare professional. The Spanish translation was then modified by public health professionals in Costa Rica to accommodate for local expressions and regional vocabulary. In order to assure that the translation accurately represented the English constructs, the Spanish questionnaire was back-translated into English by a bilingual native English speaker to assure accuracy. Then, a pre-test of the survey instrument was conducted by expert review and peer evaluation, and cognitive testing of the survey instrument was conducted among 10 hospital workers from four different hospitals in Costa Rica. These workers represented a range of education levels from the following departments: nutrition, security, maintenance, radiology, housekeeping, emergency room,
Policy implications

- Increased public awareness of the magnitude of work related injuries in developing countries is needed.

- The development of future prevention interventions to reduce the occurrence of work related injuries among healthcare workers in developing countries should be considered.

scrub technician, laundry, and nursing. The cognitive testing included a review of each item to assure that the translated item captured in Spanish the same construct as the original English, and the results showed that the translation was quite accurate. Each worker was asked to read each item out loud and discuss unclear items. The pre-testing of the survey ranged in time from 10 minutes per worker up to 45 minutes per worker. It was anticipated that the actual respondent burden would not exceed 30 minutes at the average educational level. The pre-test found that, with some modifications for local word usage, the survey questions were well understood and the response options were appropriate.

In addition to the pre-test, a pilot test was conducted in one of the non-study hospitals, using a simple random sample of 100 employees. The pilot test provided a preview of the logistical and administrative issues associated with a study of this magnitude. A $72 \%$ response rate was achieved after two days with no follow up of missing employees (data not presented). Minor changes were made to the section on work injuries and items relating to the occupational health commissions based on input from the employees participating in the pilot.

The 2000 survey was conducted at the employee's workplace with preceding notification, and unavailable employees were followed up. Participants were individually informed about the study purpose, the confidentiality of their responses, and the voluntary nature of their participation. Once participants consented, they received a sealed envelope with the questionnaire and an additional envelope to be sealed with the completed questionnaire. Of the original sample of 1000 employees, the eligible sample included 859 employees after excluding 62 employees who were no longer employed in the CCSS hospital system at the time survey was conducted, and 79 employees who were on sick leave or vacation. There were 17 workers who refused participation. Thus, a total of 842 answered the questionnaire resulting in an overall response rate of $98 \%$.

Items included in the questionnaire represented the following independent variables: worker training, work environment, job-task demands, personal protective equipment (PPE) availability, administrative controls, and selected demographic items that have been found to be significant in relation to safety climate perception as well as work injuries and safety practices. Measurement of the worker training scale included items such as available training classes, previous training history, and supervisory training history. Work environment included items related to the physical and psychosocial environment at work including temperature, noise, crowding, lighting, fear of bodily harm, verbal abuse, and hazardous exposures. Protective equipment availability was measured by items relating to the availability of protective equipment, including sharps containers and gloves. The wording of the items was general enough to be applicable to different work settings within a hospital. Administrative controls were measured by items such as availability of written safety policies, established safety committees at work, safety 
performance feedback, and safety investigations and inspections. Job-task demands focused on items that relate to job specific tasks or conditions that prevent safety practices from being observed. Safety climate was evaluated using an 11 item scale that measures management commitment to safety, support of co-workers and supervisors for safe work practices, and freedom to report safety violations at work; safety practices were measured by the level of compliance with established safety practices in hospital settings.

\section{Sociodemographic, occupational, and organisational variables}

The questionnaire included standard sociodemographic variables (sex, age, education, and occupation). For the purpose of the analysis, the following variables were categorised as occupational risk factors: whether or not the worker had direct patient contact (1 item); chemical exposure (1 item); radiation exposure (1 item); physical exposures (7 items); temperature variations, loud noise, lack of space, poor air quality, poor lighting, fall/ trip hazards, and electrical hazards; as well as biological exposures (2 items): patient blood and body fluids, and contaminated sharp objects. In addition, organisational risk factors included: type of hospital (national, regional, and peripheral); manager safety training ( 1 item); employee safety training ( 1 item); provision of personal protective equipment (PPE) (1 item); administrative controls (7 items); performance of job-task demands that interfere with safety practices (4 items); safety practices (12 items); and safety climate (11 items).

Assessment of occupational and organisational items used a five point Likert-type scale (never, rarely, sometimes, often, and always), except for safety practices which included a sixth option of "does not apply to my job" if safety practices were not relevant (that is, administrative personnel) and type of hospital, which was obtained from the CCSS. Some items were reverse scored so that all responses could be compared in the same direction. Mean scores were calculated for each scale that had more than one item. Each scale had to be at least $80 \%$ complete in order to calculate a mean scale score; otherwise the scale was set to missing. Each of the scales showed high internal consistency reliability, as measured by the Cronbach's alpha coefficient $(\alpha \geqslant 0.70)$ : administrative controls (0.75), job-task demands (0.72), safety climate $(0.81)$, and safety practices $(0.93)$. Scales were dichotomised to define exposed and non-exposed workers. Exposure was defined by responses of "often" and "always", and nonexposure was defined as "never", "rarely", and "sometimes". Following dichotomisation, safety practices and safety climate were combined to create four categories: high climate and high practices, high climate and low practices, low climate and high practices, and low climate and low practices. The category "high climate and high practices" was used as the reference group in the analyses. Two separate logistic regression models were developed: one model included safety practices and safety climate as separate variables, and the second model included the combined variable as described above, using three indicator variables.

\section{Work related injuries}

Work related injuries (WRI) were defined as the number of self-reported injuries experienced in the previous six months for the following accidental events: needlesticks, splashes to the eye or mouth, contact with contaminated material, cuts, falls, skin rashes, burns, back injuries, electrical shocks, or poisonings. WRI rates, expressed as person-six months, were computed by dividing the total number of WRI experienced for each type of injury category by the person-time at risk. An aggregated measure of WRI was calculated adding the number for each injury category. The period worked was calculated as the total number of possible working days for each employee during the six month period. Data for days not worked were not available. Open ended injury recall was not allowed, to limit the opportunity for response bias. Participants were asked to express the number of injuries experienced in the last six month period as " 0 " to " 6 or more". The response of " 6 or more" was coded as " 6 " injuries. WRI was considered to be a countable variable that can take values of $0,1,2, \ldots$ and, therefore, we assumed the number of WRI for each subject followed a Poisson distribution.

\section{Statistical analysis}

After initial screening of the responses, we identified 123 individuals who answered the entire section on safety practices as not applicable to their job. These individuals were considered not-at-risk on the basis of their job duties and removed from the analysis. An additional 231 questionnaires did not meet the $80 \%$ completion criterion, and were not included in the analysis. After these exclusions, a total of 488 at risk subjects remained. This subset included six administrative employees and seven maintenance

Table 1 Sample demographic and exposure characteristics ( $n=475)$; Costa Rica, 2000

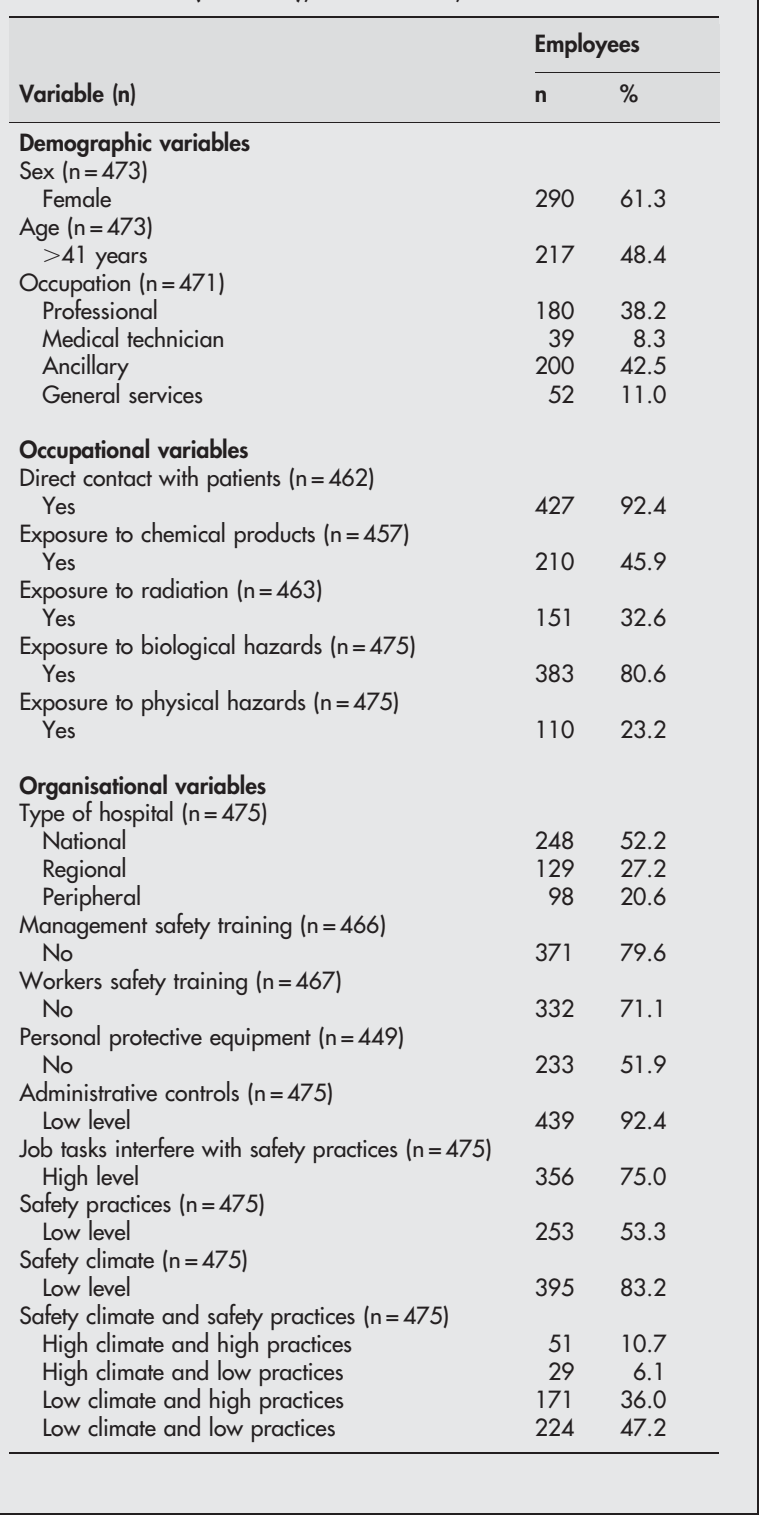


employees. Administrative employees were considered notat-risk and therefore removed from the data set. Multivariate analyses for these small occupational groups would be of limited validity, and the remaining seven maintenance workers were excluded from the analysis. The final sample consisted of 475 employees.

We assessed the differences between the final sample of workers $(n=475)$ and those excluded from the analyses $(n=367)$ using the exclusion criteria previously described, and found statistically significant differences $(p<0.05)$ between these two groups in many variables. We further analysed the differences between these two groups by separating the excluded employees into two subsets: those excluded on the basis of job tasks and those excluded because they did not met the $80 \%$ completion criterion. The results were similar and significant for the two subsets. The final sample had more females, more professionals and ancillary personnel, more employees with direct patient contact, and fewer medical technicians and general service employees. The final sample also had an overall higher exposure to occupational and organisational risk factors, and twice the work related injury rate (9.5 injuries per six person-months) than the total excluded employees (4.3 injuries) and one and a half the work related injury rate than the employees who did not meet the $80 \%$ completion criteria (5.7 injuries).

Crude and adjusted rate ratios (RR) and their 95\% confidence intervals (95\% CI) were calculated. Bivariate associations between each exposure variable and WRI were assessed. Significant $(p<0.05)$ variables were selected for inclusion in the simultaneously adjusted multivariate model. After adjustment for covariates, non-significant $(p>0.05)$ variables were removed and models were re-estimated. Log likelihood ratio tests were then performed to test the adequacy of removing those variables..$^{20}$ The Poisson distribution can cause an underestimate of the standard error due to overdispersion when the variance is greater than the mean. Since the injury data indicated a large amount of variability, to reduce the risk of committing a type I error we corrected for overdispersion. To correct for overdispersion, we used the STATA software option which sets the standard error scale to the generalised $\chi^{2}$ statistic divided by the residual degrees of freedom. All analyses were performed with STATA SE 8.2. ${ }^{21}$

\section{RESULTS}

\section{Demographic characteristics}

Table 1 presents the demographic characteristics of the study sample. The sample had more women (61\%), and 52\% were less than 42 years of age. The majority of workers $(71 \%)$ were either ancillary $(43 \%)$ or professional personnel (physician, nurse, nutritionist, physical therapist, etc) (28\%); and $92 \%$ reported having direct patient contact.

\section{Occupational and organisational risk factors}

Table 1 shows exposure to occupational and organisational risk factors. Exposures to occupational risk factors ranged from $23 \%$ of the respondents exposed to physical hazards to $81 \%$ exposed to biological hazards. Half of the employees $(52 \%)$ worked in national hospitals, $27 \%$ in regional hospitals, and $21 \%$ in peripheral hospitals, a distribution that was consistent with the overall distribution of all hospital based employees in the CCSS system (50\% national, $30 \%$ regional, and $20 \%$ peripheral).

Analysis of exposure to organisational risk factors showed that only $29 \%$ of the employees and $20 \%$ of the managers had received safety training, and less than half $(48 \%)$ of the workers reported that necessary personal protective equipment was provided. A majority (53\%) of the employees reported a low level of compliance with safety practices, and most of the sample $(75 \%)$ reported having job tasks that interfered with their ability to comply with safety practices. Almost all of the employees reported a low level of safety climate $(83 \%)$ and low administrative controls (92\%) at their workplace. Safety climate and safety practices were assessed individually and together in combination. A low level of safety climate and low level of safety practices was the most common situation (47\%).

\section{Work related injuries}

The total number of WRI experienced by the respondents was 4498 for a six month period, for an individual employee injury rate of 9.5 events every six months (table 2). Skin contact with contaminated material (1093 events by 279 employees) and back injuries ( 1048 events by 309 employees) were the two most common events, representing $48 \%$ of all injuries. When combined with eyes/mouth splashes (713 events by 233 employees) and needlesticks (637 events by 224 employees), these four types of injury accounted for nearly $80 \%$ of all WRI.

The crude RR (table 3 ) showed a higher RR of injury for the exposed groups for both the occupational and organisational variables, with RR varying from 1.30 for lack of management safety training to 2.75 for the combination of low safety climate and low safety practices. None of the demographic variables were significantly associated with WRI, and almost all of the occupational variables and all organisational variables (except for the type of hospital) were significant

Table 2 Work related injuries experienced in a six month period by public hospital based workers $(n=475)$ by type of injuries; Costa Rica, 2000

\begin{tabular}{llllll}
\hline & \multicolumn{2}{l}{ Employees* } & & \multicolumn{2}{l}{ Work related injuries } \\
\cline { 2 - 2 } \cline { 5 - 6 } Type of injury & $\mathbf{n}$ & & $\mathbf{n}$ & $(\%)$ & Rate \\
\hline Contaminated contact & 279 & 1093 & $(24.3)$ & 2.3 \\
Back injuries & 309 & 1048 & $(23.3)$ & 2.2 \\
Eye/mouth splashes & 233 & 713 & $(15.9)$ & 1.5 \\
Needlesticks & 224 & 637 & $(14.2)$ & 1.3 \\
Cuts with sharps & 144 & 354 & $(7.9)$ & 0.7 \\
Skin rashes & 106 & 280 & $(6.2)$ & 0.6 \\
Falls with injury & 65 & 114 & $(2.5)$ & 0.2 \\
Burns & 39 & 96 & $(2.1)$ & 0.2 \\
Poisonings & 47 & 93 & $(2.1)$ & 0.2 \\
Electric shocks & 25 & 70 & $(1.6)$ & 0.1 \\
Totalt & 415 & 4498 & $(100)$ & 9.5 \\
\hline
\end{tabular}

Rate, WRI rates, expressed as person-six months, were computed by dividing the total number of WRI experienced for each type of injury category by the person-time at risk. * Number of employees is not mutually exclusive.

†Computation based on the aggregated measure of work related injuries. 
Table 3 Risk of work related injuries experienced in a six month period by public hospital based workers $(n=475)$ by organisation and occupational factors; Costa Rica, 2000

\begin{tabular}{|c|c|c|c|c|c|c|c|}
\hline \multirow[b]{2}{*}{ Variable (reference) } & \multicolumn{7}{|c|}{ Work related injuries } \\
\hline & $n$ & $\%$ & Rate & RRc & $95 \% \mathrm{Cl}$ & RRa & $95 \% \mathrm{Cl}$ \\
\hline \multicolumn{8}{|l|}{ Demographic variables } \\
\hline \multicolumn{8}{|l|}{ Sex } \\
\hline Male & 1651 & 37.1 & 9.0 & 1 & & & \\
\hline Female & 2803 & 62.9 & 9.7 & 1.07 & 0.90 to 1.28 & & \\
\hline \multicolumn{8}{|l|}{ Age } \\
\hline$\leqslant 41$ years & 2341 & 55.2 & 10.1 & 1 & & & \\
\hline$>41$ years & 1901 & 44.8 & 8.8 & 0.86 & 0.73 to 1.03 & & \\
\hline \multicolumn{8}{|l|}{ Occupation } \\
\hline Professional & 1789 & 39.9 & 9.9 & 1 & & & \\
\hline Medical technician & 347 & 7.7 & 8.9 & 0.89 & 0.64 to 1.25 & & \\
\hline Ancillary & 1836 & 41.0 & 9.2 & 0.92 & 0.76 to 1.12 & & \\
\hline General services & 507 & 11.3 & 9.8 & 0.98 & 0.74 to 1.31 & & \\
\hline \multicolumn{8}{|l|}{ Occupational variables } \\
\hline \multicolumn{8}{|l|}{ Direct contact with patients } \\
\hline No & 228 & 5.2 & 6.5 & 1 & & 1 & \\
\hline Yes & 4144 & 94.8 & 9.7 & 1.49 & 1.01 to 2.20 & 1.12 & 0.76 to 1.67 \\
\hline \multicolumn{8}{|l|}{ Exposure to chemical products } \\
\hline No & 1889 & 43.3 & 7.6 & 1 & & 1 & \\
\hline Yes & 2478 & 56.7 & 11.8 & 1.55 & 1.31 to 1.82 & 1.36 & 1.13 to 1.62 \\
\hline \multicolumn{8}{|l|}{ Exposure to radiation } \\
\hline No & 2534 & 57.6 & 8.1 & 1 & & 1 & \\
\hline Yes & 1867 & 42.4 & 12.4 & 1.52 & 1.29 to 1.80 & 1.09 & 0.91 to 1.31 \\
\hline \multicolumn{8}{|l|}{ Exposure to biological hazards } \\
\hline No & 573 & 12.7 & 6.3 & 1 & & 1 & \\
\hline Yes & 3925 & 87.3 & 10.3 & 1.65 & 1.28 to 2.12 & 1.16 & 0.89 to 1.50 \\
\hline \multicolumn{8}{|l|}{ Exposure to physical hazards } \\
\hline No & 3068 & 68.2 & 8.4 & 1 & & 1 & \\
\hline Yes & 1430 & 31.8 & 13.0 & 1.55 & 1.29 to 1.85 & 1.26 & 1.04 to 1.52 \\
\hline \multicolumn{8}{|l|}{$\begin{array}{l}\text { Organisational variables } \\
\text { Type of hospital }\end{array}$} \\
\hline National & 2435 & 54.1 & 9.8 & 1 & & & \\
\hline Regional & 1263 & 28.1 & 9.8 & 1.00 & 0.82 to 1.21 & & \\
\hline Peripheral & 800 & 17.8 & 8.2 & 0.83 & 0.66 to 1.05 & & \\
\hline \multicolumn{8}{|l|}{ Management safety training } \\
\hline Yes & 730 & 16.5 & 7.7 & 1 & & 1 & \\
\hline & 3703 & 83.5 & 10.0 & 1.30 & 1.03 to 1.63 & 0.83 & 0.65 to 1.07 \\
\hline \multicolumn{8}{|l|}{$\begin{array}{l}\text { No } \\
\text { Workers safety training }\end{array}$} \\
\hline Yes & 895 & 20.1 & 6.6 & 1 & & 1 & \\
\hline No & 3552 & 79.9 & 10.7 & 1.61 & 1.31 to 1.99 & 1.41 & 1.11 to 1.78 \\
\hline Personal protective equipment & & & & & & & \\
\hline Yes & 1740 & 40.7 & 8.1 & 1 & & 1 & \\
\hline No & 2539 & 59.3 & 10.9 & 1.35 & 1.14 to 1.60 & 1.09 & 0.92 to 1.30 \\
\hline Administrative controls & & & & & & & \\
\hline High level & 228 & 5.1 & 6.3 & 1 & & 1 & \\
\hline Low level & 4270 & 94.9 & 9.7 & 1.54 & 1.05 to 2.25 & 0.94 & 0.64 to 1.37 \\
\hline Job tasks interference & & & & & & & \\
\hline Low level & 689 & 15.3 & 5.8 & 1 & & 1 & \\
\hline High level & 3809 & 84.7 & 10.7 & 1.85 & 1.47 to 2.32 & 1.46 & 1.16 to 1.86 \\
\hline Safety practices & & & & & & & \\
\hline High level* & 1730 & 38.5 & 7.8 & 1 & & 1 & \\
\hline Low level & 2768 & 61.5 & 10.9 & 1.40 & 1.19 to 1.66 & 1.27 & 1.07 to 1.51 \\
\hline Safety climate & & & & & & & \\
\hline High level* & 355 & 7.9 & 4.4 & 1 & & 1 & \\
\hline Low level & 4143 & 92.1 & 10.5 & 2.36 & 1.75 to 3.20 & 1.51 & 1.06 to 2.15 \\
\hline Safety climate and safety practices & & & & & & & \\
\hline High climate and high practices* & 218 & 4.8 & 4.3 & 1 & & 1 & \\
\hline High climate and low practices & 137 & 3.0 & 4.7 & 1.11 & 0.62 to 1.99 & 1.27 & 0.67 to 2.42 \\
\hline Low climate and high practices & 1512 & 33.6 & 8.8 & 2.07 & 1.40 to 3.05 & 1.51 & 0.96 to 2.36 \\
\hline Low climate and low practices & 2631 & 58.5 & 11.8 & 2.75 & 1.88 to 4.01 & 1.92 & 1.23 to 3.00 \\
\hline
\end{tabular}

RRc, crude rate ratio of work related injuries; RRa, adjusted rate ratio for the significant $(p<0.05)$ variables on the bivariate crude analysis.

*Two separate logistic regression models were developed: one model included safety practices and safety climate as separate variables, and the second model included the combined variable of safety climate and safety practices. The estimations for the second model did not vary significantly so data for the rest of covariates presented in the table correspond to results using the first model.

$(\mathrm{p}<0.05)$ in the bivariate analysis. Only those factors with crude RR that were significantly related to WRI were entered into the multivariate model.

After simultaneous multivariate adjustment, the following variables lost significance: direct patient contact, exposure to radiation, biological hazards, lack of management safety training, lack of needed protective equipment, and the existence of administrative controls. The log likelihood ratio tests comparing the final multivariate models before and after removing non-significant variables were significant $(p>0.05)$, and models containing the non-significant variables are presented. Exposure to chemical products $(\mathrm{RR}=1.36)$ and to physical hazards $(\mathrm{RR}=1.26)$ had higher WRI risk than non-exposed employees. Employees with job task that interfere with their ability to comply with safety practices $(\mathrm{RR}=1.46)$ and those with a lack of safety training 
$(\mathrm{RR}=1.41) \quad$ experienced higher injury risk than their counterparts with low job task interference and a history safety training respectively. Safety practices and safety climate were assessed individually and in combination and were almost always significantly correlated with WRI. When assessed individually low safety climate had a $R R=1.51$ and low safety practices a $R R=1.27$ when compared to high levels in their respective scales. Finally, employees who reported a low level of safety climate in combination with low safety practices showed the highest association with WRI $(\mathrm{RR}=1.92)$.

\section{DISCUSSION}

To our knowledge, this is the first study exploring the relation between several occupational and organisational risk factors and the occurrence of WRI among public hospital employees in Costa Rica. The main findings showed exposure to occupational factors (chemical and physical hazards) and to organisational factors (lack of safety training and low levels of safety climate and safety practices) to be significantly related to higher rates of WRI. In addition, the association with WRI was observed to be more pronounced for organisational factors than for the occupational risk factors.

The higher relative influence of organisational factors over occupational factors for WRI, together with the lack of significance of demographic variables, is an interesting finding. For the purposes of this study, we considered safety practices an organisational variable, due to the strong influence organisational level constructs have on individual safety practices. ${ }^{15} 18$ Together with safety climate (another organisational level construct) the interaction of low levels of both safety practices and safety climate showed the highest association with WRI in the present research, suggesting that the lower the safety climate and the safety practices are in the workplace, the higher the WRI rate. Despite the tendency of the work injury research literature to focus on the relation between individual and occupational risk factors, our findings are consistent with other studies ${ }^{15}{ }^{17} 22$ which underscore the importance of organisational factors in relation to work related injuries. The non-significant effects of demographic variables and some occupational variables support the theory that organisational variables play a significant role in predicting injury risk, and a more significant role than occupational risk factors alone.

This research also shows the relative importance of safety climate and/or safety practices in determining an injury risk profile for hospital workers. When evaluated together, high levels of either safety climate or safety practices were protective of injury risk, and low levels of both had the most significant effect on injury rates. This suggests that workplace interventions aimed at injury reduction should include strategies to improve both safety climate and safety practices.

Caution is recommended when interpreting these findings. The cross-sectional design of the study does not allow for determining causality in either direction (that is, work organisation and occupational factors influence WRI or vice versa). ${ }^{23}$ Data were self-reported and measured retrospectively for a six month period which may introduce biases, such as recall bias or the tendency to report socially acceptable responses. Due to the lack of reliable and valid injury registries in developing countries, self-reports were the only way to obtain the data presented in this paper. The potential overestimate of the number of injuries experienced by employee was mitigated by limiting the number of injuries reported to a maximum of six injuries during the last six months for each injury category. The lack of data for days not worked may have resulted in an overestimate of the persontime at risk. Given the six month time period under investigation and the stability of the study population, these limitations are not considered to be significant. Additionally, the creation of scales, which were standard and had been previously validated, was restricted to subjects with $80 \%$ of the scale complete and exhibited good internal consistency. These factors should have attenuated the impact of some of the biases.

Despite all these factors, non-response bias cannot be completely ruled out. The initial response rate was high $(98 \%)$, but we were unable to use 231 questionnaires since they did not meet the $80 \%$ of scale items completion criteria to compute the scales of interest in our study. Taking this into consideration, the response rate declines to $71 \%$, which still is a high value. As commented in the methods section, the excluded group was considered to be a not-at-risk group that was shown to be significantly different when compared to the final sample $(n=475)$; they had a greater proportion of occupations with less direct patient contact (that is, more administrative and maintenance personnel, medical technicians, and general service employees); they had overall less exposure to occupational and organisational risk factors, and half the work related injury rate. The $80 \%$ completion criterion was used to increase the validity of the response scales. Less restrictive completion criteria would have allowed for inclusion of incomplete data that would bias the analyses toward the null, thus making easier to commit a type II error. ${ }^{17}{ }^{24}$

With regard to the potential for selection bias, two effects should be considered..$^{25}$ First, a healthy worker effect might be present since some employees (that is, those employees on sick leave, vacation, or no longer employed) were not available for the interview. This potential bias would have underestimated the associations as respondents would be healthier, and possibly have fewer injuries than non-respondents. Second, the final sample had more exposure to occupational and organisational risk factors, and higher levels of work related injury than the employees who were excluded from the analysis. Most of those excluded from the analysis reported having no direct contact with patients on the job. The study findings are therefore generalisable to the hospital based employees of the Costa Rican public hospital system with direct patient contact, but not necessarily generalisable to employees with no patient contact.

To confirm the present findings further research is needed. Our group is working to conduct additional research using a prospective longitudinal design that may provide better insight into the occurrence of WRI in this study setting. Given the hierarchical structure of most work organisations, multilevel techniques are the best methodological approach compared to other research methods. ${ }^{22}$ Multilevel models provide a more appropriate approach to examine how work organisation can affect individual and organisational safety behaviour and their associations with work related injuries.

In summary, this research contributes to the scientific literature of the relation between organisational factors and workplace injury. A better understanding of this relation is increasingly important as we look to prevention interventions to reduce the burden of occupational injury. The study findings should help guide prevention intervention efforts and may be useful to public hospital systems in developing countries throughout Latin America, with the necessary adaptation to the diverse cultural and work settings in other countries in the region. Finally, these results provide important data for the development of training programmes designed to improve the safety outcomes of work organisation and to reduce exposure to occupational risk factors in the public hospital system. 


\section{Authors' affiliations}

D Gimeno, S Felknor, K D Burau, G L Delclos, Southwest Center for Occupational and Environmental Health, The University of Texas School of Public Health, Health Science Center at Houston, Texas, USA

Funding: supported in part by the Fogarty International Center Training Grant 3 D43 TW00644

Competing interests: none declared

\section{REFERENCES}

1 Zohar D. Safety climate in industry organizations: theoretical and applied implications. J Appl Psychol 1980;65:96-102.

2 Zohar D. A group-level model of safety climate: testing the effect of group climate on microaccidents in manufacturing jobs. J Appl Psychol 2000;85:587-96.

3 Cohen A, Smith M, Cohen HH. Safety program practices in high vs. low accident rate companies - an interim report. Cincinnati, $\mathrm{OH}$ : US Dept HEW, $\mathrm{NIOSH}, 1975: 75-185$.

4 Smith MJ, Cohen HH, Cohen A, et al. Characteristics of successful safety programs. J Saf Res 1978;10:5-15.

5 DeJoy DM, Gershon RRM, Murphy LR. Minimizing the risk of occupationally acquired HIV/AIDS: universal precautions and health-care workers. In: Feyer AM, Williamson A, eds. Occupational injury: risk, prevention and intervention. London: Taylor \& Francis, 1998:107-15.

6 Gershon RR, Vlahov D, Felknor SA, et al. Compliance with universal precautions among health care workers at three regional hospitals. Am J Infect Control 1995;23:225-36.

7 DeJoy DM, Murphy LR, Gershon RRM. Safety climate in health care settings In: AC Bittner, PC Champney, eds. Advances in industrial ergonomics and safety VII. New York: Taylor \& Francis, 1995:923-9.

8 Gershon RRM, Karkashian CD, Vlahov D, et al. Compliance with universal precautions in correctional health care facilities. J Occup Environ Med 1999;41:181-9.

9 Gershon R, Karkashian C, Vlahov D, et al. Correlated of infection control practices in dentistry. Am J Infect Control 1998;26:29-34.

10 McGovern PM, Kochevar LK, Vesley D, et al. Laboratory professionals' compliance with universal precautions. Lab Med 1997; 28:725-30.
11 Kelen G, DiGiovanna TA, Celantano DA. Adherence to universal (barrier) precautions during interventions on critically ill and injured emergency department patients. J AIDS 1990;3:987-94.

12 Hersey JC, Martin LS. Use of infection control guidelines by workers in healthcare facilities to prevent occupational transmission of HBV and HIV: results of a national survey. Infect Control Hosp Epidemiol 1994; 15:243-52.

13 Michaelson A, Delclos GL, Felknor SA, et al. Compliance with universal precautions among physicians. J Occup Environ Med 1997;39:130-7.

14 Murphy L, Grosch J, Gershon R, et al. Safety climate and injuries: the case of occupational exposure to HIV. In: Seppala P, Luopajarvi T, Nygard CL, Mattila M, eds. From experience to innovation (Volume 5). Human computer interaction, stress and mental load, aging and occupational health. Tampere, Finland: Finnish Institute of Occupational Health, 1997:666-8.

15 Gershon RR, Karkashian CD, Grosch JW, et al. Hospital safety climate and its relationship with safe work practices and workplace exposure incidents. Am J Infect Control 2000;28:211-21.

16 Gershon RR, Pearse L, Grimes M, et al. The impact of multifocused interventions on sharps injury rates at an acute-care hospital. Infect Control Hosp Epidemiol 1999;20:806-11.

17 Felknor SA, Aday LA, Burau KD, et al. Safety climate and its association with injuries and safety practices in public hospitals in Costa Rica. Int J Occup Environ Health 2000;6:18-25.

18 Griffin MA, Neal A. Perceptions of safety at work: a framework for linking safety climate to safety performance, knowledge, and motivation. J Occup Health Psychol 2000;5:347-58

19 DeJoy DM, Gershon RM, Murphy LR, et al. A work systems analysis of compliance with universal precautions among health care workers. Health Educ Q 1996;23:159-74.

20 Hosmer DW, Lemeshow S. Applied logistic regression, 2nd edn. New York: Wiley, 2000.

21 StataCorp. Stata Statistical Software: Release 8.0. College Station, TX: Stata Corporation, 2003.

22 Zohar D. Safety climate: conceptual and measurement issues. In: Quick JC, Tetrick LE, eds. Handbook of occupational health psychology. Washington, DC: American Psychological Association, 2003:123-42.

23 Szklo M, Nieto FJ. Epidemiology. Beyond the basics. Gaithersburg: Aspen Publishers, 2000

24 Kristensen TS. Job stress and cardiovascular disease: a theoretic critical review. J Occup Health Psychol 1996;1:246-60.

25 Checkoway H, Pearce NE, Crawford-Brown DJ. Research methods in occupational epidemiology, 2nd edn. New York: Oxford University Press, 2004. 